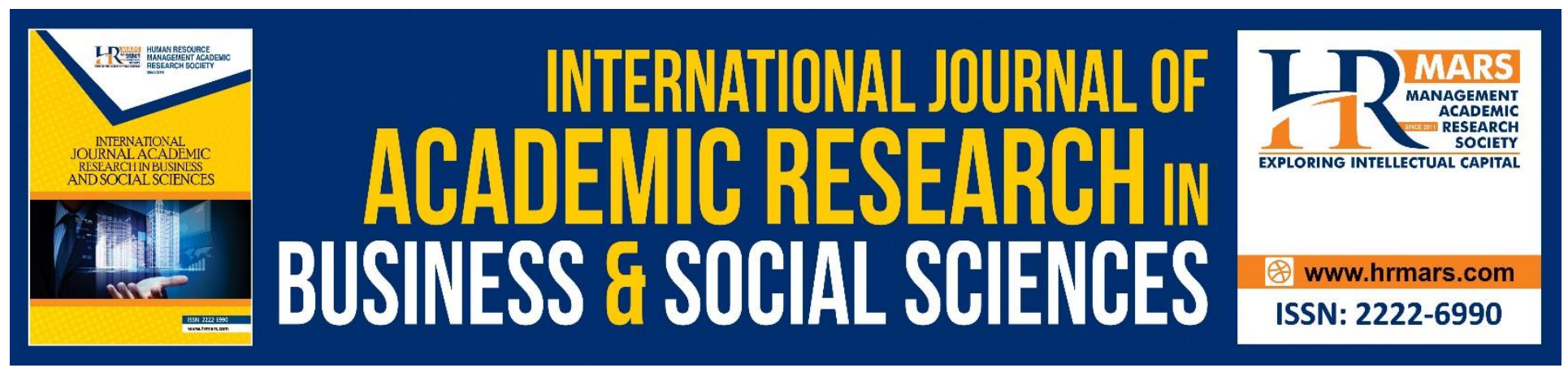

\title{
Influence of Environmental Knowledge and Attitude on Employee Green Behaviour
}

\section{Siti Norashikin Bashirun, Shereen Noranee}

To Link this Article: http://dx.doi.org/10.6007/IJARBSS/v10-i6/7463

DOI:10.6007/IJARBSS/v10-i6/7463

Received: 02 April 2020, Revised: 22 May 2020, Accepted: 09 June 2020

Published Online: 29 June 2020

In-Text Citation: (Bashirun \& Noranee, 2020)

To Cite this Article: Bashirun, S. N., \& Noranee, S. (2020). Influence of Environmental Knowledge and Attitude on Employee Green Behaviour. International Journal of Academic Research in Business and Social Sciences, 10(6), 937-946.

Copyright: (C) 2020 The Author(s)

Published by Human Resource Management Academic Research Society (www.hrmars.com)

This article is published under the Creative Commons Attribution (CC BY 4.0) license. Anyone may reproduce, distribute, translate and create derivative works of this article (for both commercial and non-commercial purposes), subject to full attribution to the original publication and authors. The full terms of this license may be seen at: http://creativecommons.org/licences/by/4.0/legalcode

Vol. 10, No. 6, 2020, Pg. 937 - 946

Full Terms \& Conditions of access and use can be found at http://hrmars.com/index.php/pages/detail/publication-ethics 


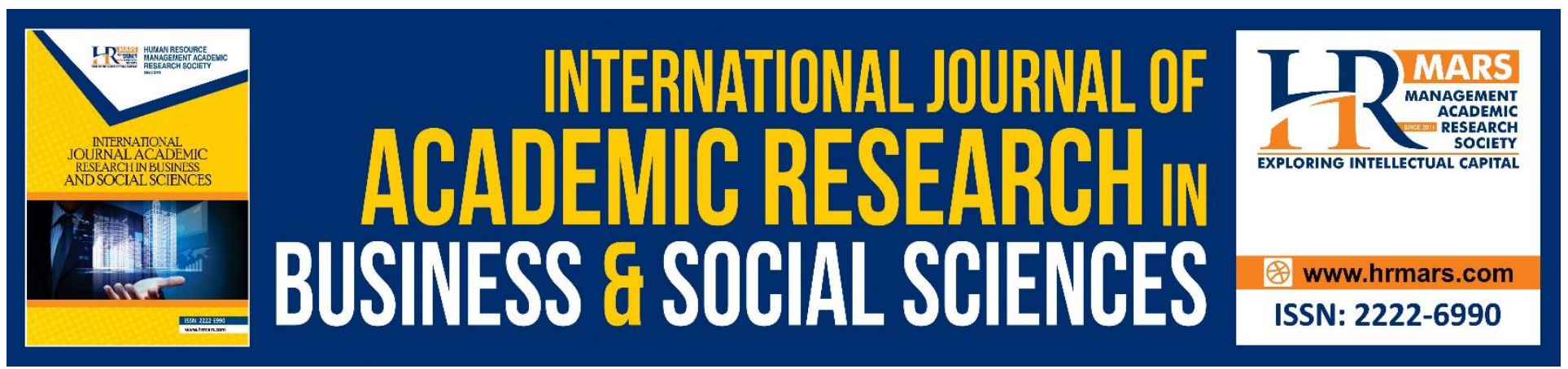

\title{
Influence of Environmental Knowledge and Attitude on Employee Green Behaviour
}

\author{
Siti Norashikin Bashirun \\ Faculty of Business and Management, Universiti Teknologi MARA, Melaka \\ Malaysia \\ Shereen Noranee \\ Faculty of Business and Management, Universiti Teknologi MARA, Selangor \\ Malaysia
}

\begin{abstract}
Environmental issues often get global attention due to increasing environmental damages as seen in global warming, environmental degradation and ozone depletion. By encouraging proenvironmental or green behaviour at workplace, it can encourage the employees to be more responsible in reducing environmental problems. Thus, the issue of employee green behaviour (EGB) has been a topic of interest among scholars in management. The aim of this study is to examine the relationship between employee environmental knowledge and environmental attitude towards employee green behaviour at workplace. The data comprised responses from 108 employees that indicated a moderate level of green practices at work. The study found that there is no relationship exists between environmental knowledge (EK) and environmental attitude (EA) on employee green behaviour (EGB). Future recommendations on the practical implication to help encourage employee to be engaged with green behaviour at work were later discussed.

Keywords: Employee Green Behaviour, Environmental Knowledge, Environmental Attitude, ProEnvironmental Behaviour, Environmental Sustainability.
\end{abstract}

\section{Introduction}

Environmental sustainability issues have become one of the debated and significant topics over the years. In fact, the trends that advocate the use of green product, green building, green technology, green ecotourism and sustainable consumption have become important agendas among organisations, society and the government. The changes in socio demographic and economic structures have influenced the green practices in industry directly and indirectly, and these changes are needed to fulfill the demand of the growing population. Therefore, companies start to make tremendous advances in applying green practices (Phuah, 2013) in their company. Subsequently, climate change has become the most prominent environmental health risk and it is also the most crucial issue in the $21^{\text {st }}$ century (World Health Organization, 2015). Statistic from SWCorp Malaysia 
in 2017 highlighted that Malaysians generated about 37500 tons solid waste per day and that involved management cost of RM2.0 billion a year. This indicates a need for the community, particularly the young generation, to seriously look into this matter. Until now, government and Nongovernmental Organisations (NGOs) in Malaysia are still actively promoting communication campaigns and strategies (e.g. Go Green Campaign, no plastic, no straw, etc.) in hope to disseminate knowledge that would enlighten citizen to lead a more positive behaviour.

To combating this issue, the responsibility cannot solely be put on the government, but with the organisations commitment as well. Hence, there is the essential to study pro-environmental behaviour (PEB), as organisations are the major contributors towards environmental problems (Hoffman \& Georg, 2013). As employee in general spends one third in a day in the workplace, proenvironmental behaviour can be studied in workplace setting (Stern, 2000). A number of studies have found that the individual's employee green behaviour would significantly contribute to wider outcomes of environmental sustainability, mainly when it is combined with established environmental management systems (EMS) and innovations (Norton et al., 2014; Ones \& Dilchert, 2012b). Previous scholars (Norton et al., 2014; Suganthi, 2019) stated the need to explore environmental friendly behaviour among employees as it is an important aspect to reach sustainability for the organization. Furthermore, practicing green behaviour is a good way in marketing and promoting good public image and strong ethics of corporate social Responsibility (CSR). As highlighted by Hens et al., (2018), practicing CSR that reflects environmental behaviour is one of the ways in achieving greener environment in organization.

This preliminary study had selected employees from a private organization because since green growth is one of the attentions in the Sustainability Development Goals (SDG) for sustainability in socio-economic development. To respond with this objective, one of the strategies to greening the organization is through changing employee behaviours as stated by Loverock, (2010), that believed that changing employees' behaviour at workplace may influence their behaviour outside work, and ultimately becomes an effective driver in achieving sustainable social change. Hence, the objectives of this study are:

1. To identify the level of employee's green behaviour at work.

2. To determine the relationship between employee environmental knowledge and green behaviour at work.

3. To determine the relationship between employee environmental attitude and green behaviour at work.

\section{Literature Review}

\section{Employee Green Behaviour (EGB)}

Organizational researchers and practitioners have taken an interest in pro-environmental behaviour or "green behaviour" at work due to the overwhelming issue on climate change and environmental sustainability. Stern, (2000) defines employee green behaviour (EGB) as behavioural intention that propel people to take action to reduce the negative impact on the environment. EGB is defined as a workplace-specific form of pro-environmental behaviour in employees, and it is categorised into required employee green behaviour, and voluntary employee green behaviour, defined as a workplace-specific form of pro environmental behaviour (Norton et al., 2015). Bissing-Olson, Iyer, Fielding, and Zacher (2013) propose two different types of EGB, task-related (e.g. effort that is 
related to the core tasks of the employee) and proactive behaviour (e.g. the amount to which employees take initiative to engage in environmentally friendly behaviours). Steg and Vlek (2009) define "green" as the environmentally friendly behaviour of an individual, who seeks activities that minimised the effect of damage, and he or she will seek activities that benefit the natural environment. Examples of EGB in the workplace are numerous, such as turning off lights when leaving the office, using teleconference, printing draft on scrap paper, and spread the information regarding environmental behaviour among co-workers.

Ones and Dilchert (2013) classify green behaviours into five categories of "Green Taxonomy" to measure employee green behaviour at work. The five categories are (1) conserving; (2) work sustainably; (3) avoiding harm; (4) influencing others; and (5) taking initiative. Fostering employee green behaviour at work could be one of the factors that can help to deal with environmental issue (Lamm et al. 2013). When pro-environmental behaviour is carried out in relation to the individuals' jobs, employee is prone to engage in more pro-environmental behaviour at workplaces (Ones \& Dilchert, 2012), and eventually, this would turn to an organizational culture that prioritised environmental awareness and encourage on pro-environmental behaviour at workplace (Sanyal, Bengal, \& Bengal, 2017).

Recently, researchers have emphasised the need to examine employee green behaviour (EGB) and its individual and contextual predictors from a multilevel perspective (Kim, Han, Jackson, \& Ployhart, 2014; Norton et al, 2015). Rezai (2013) states that people have positive perception towards green concept, and they agreed that going green could improve human health as the environment has a direct impact on the human life. EGB can also be undertaken outside of formal duties and responsibilities in work settings, and $O C B$ are not a part of core task performance, but doing so can help the organizational operation (Organ, Podsakoff, \& MacKenzie, 2006). The fast movement of the climate change offers a competitive advantage to the firm who are effective in managing their operations towards environmental sustainability agenda. Examples of green initiative activities including introducing business conducts that are aimed to conserving the environment and implementing 'green office concept' in its daily operations and this can lead employee to perform greener behaviours (e.g. recycling, energy conservation, etc.). Employees' green behaviour (EGB) is one of the strategies adopted by organisations to improve their environment sustainability performance (DuBois \& Dubois, 2012).

\section{Environmental Knowledge and Attitude}

Environmental knowledge (EK) is an underlying variable that contributes to pro-environmental behaviour. The role of knowledge is important, given that controlling environmental impact is viewed as a responsibility for all employees (Florea, Cheung \& Herndon 2013). (Kollmuss \& Agyeman, 2002) categorised environmental knowledge and awareness are the internal factors that affect environmental behaviour. Awareness is considered as knowing the effect of people behaviour on the environment and this would likely affect an individual's self-consciousness as the person becomes interested in protecting the environment, to the extent that he or she may perceive it as a central component of his or her job. Levine and Strube (2012) found that knowledge is closely related to behaviour. Employees with environmental awareness would display more positive behaviour about their environment and they would be inclined to behave in an environmentally friendly manner in 
both their work and personal lives. Corporate environmental strategy is one of the factors that influences pro-environmental behaviour, in which the organisation makes it a part of their employee's responsibility to engage in environmentally friendly behaviours. This between-persons variable refers to employees' awareness and knowledge about their organisation's strategy and approach regarding environmental sustainability (Ramus \& Steger, 2000). Parallel with (Dumont et al., 2016; Norton et al., 2014), strengthening employees' awareness and knowledge towards the existence of the organisation's corporate environmental strategy would positively predicts EGB.

Hence, environmental knowledge can be embedded through organizational culture, policy, work description, or face-to-face interactions with others including the stakeholders.

Raising awareness and educating employees about the importance of EGB and the benefits of natural environment towards business outcomes are needed to boost employees' behavioural intentions to engage EGB at work (Holme \& Watts, 2000). Supported by Chan et al., (2014), who performed a study in the context of the hotel industry, strengthening employees' environmental awareness would enhance employee's environmental concern, especially regarding implementing green practices in hotel industry. Lack of knowledge of green behaviours in the workplace is one of the personal barriers among employees to perform green behaviours at workplace (Saifulina \& Carballo-Panela, 2017; AlShemmeri \& Taylor, 2017; Chan et al, 2014). By enhancing this awareness, it might help employees to engage in green practices that would reduce the effects of environmental problems in organisation.

Milfont \& Duckitt, (2010) describe environmental attitudes (EA) as the mental propensity that is expressed by people evaluative responses to the environment with some degree of favour or disfavour. Perlstring (1997) defines environmental attitude as learned tendencies in the form of consistent behaviours against environment, either positively or negatively. Previous studies found positive relationship in environmental attitude on EGB in the context of between-persons level (Bissing-Olson et al., 2013; Norton et al., 2014). Environmental attitude has been shown to give a significant impact on employee green behaviour (Scherbaum et al., 2008). While Murtagh et al. (2013), mentioned attitude is significantly related to energy saving behaviour. The conceptual framework for this study is shown in Figure 1, and this framework is based on environmental knowledge and attitude on employee green behaviour at work.

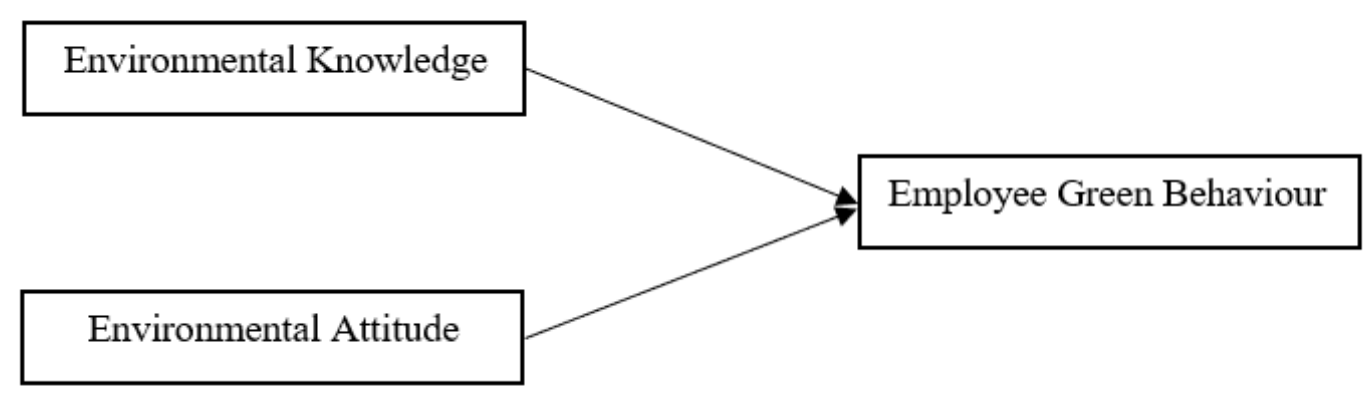

Figure 1: Conceptual Framework 
INTERNATIONAL JOURNAL OF ACADEMIC RESEARCH IN BUSINESS AND SOCIAL SCIENCES

Vol. 10, No. 6, June, 2020, E-ISSN: 2222-6990 @ 2020 HRMARS

\section{Methods and Procedure}

This is a descriptive study investigating environmental knowledge and attitudes of employee. This study was conducted among 108 employees from private organisation. Convenience sampling technique was used during data collection. Table 1 shows the characteristics of the samples for this study. The Statistical Package for Social Science (SPSS) version 23 was used to analyse and test the relationship in order to determine the relative association between the studied variables.

Table 1: Characteristics of the samples

\begin{tabular}{lcc}
\hline & Frequency & (\%) \\
\hline Gender & 62 & 57.40 \\
Male & 46 & 42.60 \\
Female & & \\
Age & 35 & 32.40 \\
31 to 40 years old & 33 & 30.60 \\
41 to 50 years old & 30 & 27.80 \\
20 to 30 years old & 10 & 9.30 \\
51 years and above & & \\
Level of Study & 52 & 48.10 \\
Bachelor Degree & 28 & 25.90 \\
Diploma & 21 & 19.40 \\
SPM & 4 & 3.70 \\
STPM & 3 & 2.80 \\
Master Degree & & \\
Department of Work & 29 & 26.90 \\
Human Resource & 26 & 24.10 \\
Administration & 18 & 16.70 \\
Company Affairs & 18 & 16.70 \\
Finance & 17 & 15.70 \\
Account & & \\
\hline
\end{tabular}

Table 2: Reliability Statistics

\begin{tabular}{cccc}
\hline Variables & Cronbach's Alpha & No of items & Level of Strength \\
\hline $\begin{array}{c}\text { Environmental } \\
\text { knowledge }\end{array}$ & .788 & 10 & Good \\
$\begin{array}{c}\text { Environmental } \\
\text { awareness } \\
\text { Green behaviour }\end{array}$ & .913 & 18 & Excellent \\
\hline
\end{tabular}

The reliability of a measure was established by testing for both consistency and stability. The consistency indicates how well items or variables hang together as a set. Cronbach's alpha is a reliability coefficient that indicates how well the items in the set are positively correlated to one another. A Cronbach's alpha that is valued above 0.7 indicates a good internal reliability (Sekaran, 2010). Table 2 shows that the value of Cronbach's alpha in this study is 0.7 after removing the items 
INTERNATIONAL JOURNAL OF ACADEMIC RESEARCH IN BUSINESS AND SOCIAL SCIENCES

Vol. 10, No. 6, June, 2020, E-ISSN: 2222-6990 @ 2020 HRMARS

which is not applicable for this study (I join tree planting and I join the earth hour). Therefore, the constructs were considered to have acceptable reliability.

\section{Results and Findings}

As the dependent variable, employee green behaviour (EGB) has the mean score of 2.84 (s. $d=0.216)$, indicating the moderate level of practices, while the independent variable, employee environmental knowledge (EK) has the mean score of 4.06, and employee environmental awareness (EA) mean score was valued at 4.22 . Table 3 shows the output that confirms that the correlation is not significant between EK and EGB $(r=-0.114)$ with $p$-value 0.241 . The mean score of EK on green was valued at 4.06, indicating that employee knowledge on green was at higher level, however it does not guarantee any establishment of a relationship. It was found that there was a negative correlation between EK and EGB, and this showed an inverse relationship between EK and EGB. Thus, the higher EK will be, the lower EGB will be with $11 \%$ correlation. Pearson $r$ is negative, which means as one variable increases in value, the second variable would decrease in value and hence, and this would show negative correlation or inverse in relationship. The result of the correlation is not significant and there was no relationship between employee's awareness EA and EGB $(r=-0.042)$ with $p$-value 0.670 . This shows that the correlation is not significant since .241 was way over the usual cut off for statistically significant (0.05). The result also indicated negative correlation between EA and EGB with $4 \%$ correlation only.

Table 3: Means, Standard Deviations and Correlations Result

\begin{tabular}{|l|c|c|c|c|}
\hline Variables & $\begin{array}{c}\text { Pearson } \\
\text { Correlation }\end{array}$ & $\begin{array}{c}\text { Sig. (2 } \\
\text { tailed) }\end{array}$ & Mean & $\begin{array}{c}\text { Standard } \\
\text { Deviation }\end{array}$ \\
\hline Environmental Knowledge (EK) & -.114 & .241 & 4.06 & $0 . .560$ \\
\hline Environmental Attitude (EA) & -.042 & .670 & 4.22 & 0.929 \\
\hline Employee Green Behaviour (EGB) & - & - & 2.84 & 0.216 \\
\hline
\end{tabular}

\section{Discussion}

It was expected that employees with environmental knowledge (EK) and environmental awareness (EA) will be more engage on green behaviour. However, results show moderate level of EGB and this are consistent with (Sadik \& Sadik, 2014). Based on the results described in this study, contrary to expectations, this study did not find a significant correlation between environmental knowledge (EK) and environmental attitude (EA) towards employee green behaviour (EGB). Increases in knowledge and having positive thought is not sufficient to lead people pro-environment behaviour (Owens, 2009; Bamberg, 2003; Erten, 2005; Sadık \& Çakan, 2010). This shows that changing behaviour is a monumental task. Human behaviour will take times to change and there are other factors that might influence these changes. Supported by Kollmuss and Agyeman, (2002), based on the Linear Model of pro-environmental behaviour argued that in most cases, any increase in knowledge would not lead to pro-environmental behaviour. Any attempt to change a habit, even a minor change, would require experiencing difficulties, even though the new behaviour would have distinct advantages over the old one. As Young et al, (2013) said, attitude change would not directly influence behaviour change in the workplace. The reason could be that the fact that people might be affected by other factors such as social, cultural, and economic that would determine how they choose to behave and perform in supporting the environmentally friendly behaviour. 
The findings of the current study are consistent with those of Lo, Peters, van Breukelen, and Kok (2014) who found that attitude is not always the strongest predictor of intention for office energysaving behaviours. Another study from Schaper (2002) showed that no relationship on personal environmental attitudes towards the environmental performance. Therefore, the reason why there was no correlation found between environmental knowledge and attitudes of EGB in this study is because their workplace environment is not effective and influential enough to encourage the attitudes. Environmental attitude and behaviour do not seem to be positively correlated in this study. This result represents that a strong environmental attitude level would not indicate greater environmental behaviour level (Mei, Wai, \& Ahamad, 2016).

Two other factors that influenced environmental attitude are age and the years of education (Kollmuss and Agyeman, 2002). Other scholars mentioned environmental attitudes are also influenced by the external or contextual factors such as laws and regulations, available technology or advertising (see example Norton, 2015). Hence, to enhance green practices, the firm should educate employees through training activities to cultivate the green behaviour at work. Abdullah, MA et al (2017), in his findings has shown that organisation must form an awareness program among employees to educate them about the importance of environmental sustainability to the firm's performance. Similar with E. S. W. Chan and Hawkins (2010), environmental awareness can be developed through environmental education or training given by the organisation to their employee. This would definitely play a role in shaping employees to become more environmentally friendly at work. Organisation must acknowledge their employee green practices by rewarding them through strong performance evaluation. According to Norton et al (2016), by enhancing the moderating effect of green psychological climate between employee's environmental knowledge and awareness, it could enhance their company's corporate environmental strategy, and this would indirectly affect their behavioural intention on EGB. In line with (Id, Hine, \& Id, 2019) that green work climates support the EGB at workplace.

Studies on employee green behaviour and environmentally friendly is mainly based on the Western perspective. Therefore, any differences in culture and regulatory might affect companies in different countries, as research indicates that environmental beliefs, knowledge, and attitudes are varied around the world (e.g., see Aoyagi-Usui, Vinken, \& Kuribayashi, 2003). To sum up, the results of this study show that environmental knowledge and positive attitude of employee are not sufficient to influence the employee to put them to practice.

\section{Conclusions}

Several limitations to this preliminary study need to be acknowledged. Employees from a wider range and in different sectors may present different perspective of the findings. Therefore, in future research, the respondents from different industries or sectors should be explored. With the purpose to ensure the result to become more reliable, it is suggested that future study should link the existing variable with mediating variables that could enhance the relationship on employee green behaviour. To date, there is a paucity on studies regarding the antecedents of pro-environmental behaviour at work (Boiral \& Paille 2013, Norton, Zacher, \& Ashkanasy, 2012), and this research will serve as a base for future studies on EGB in Malaysia, either in public or private organisation. The current findings would add substantially to our understanding and to fill the gap between EK and EA towards EGB. 
INTERNATIONAL JOURNAL OF ACADEMIC RESEARCH IN BUSINESS AND SOCIAL SCIENCES

Vol. 10, No. 6, June, 2020, E-ISSN: 2222-6990 @ 2020 HRMARS

Finally, this study will extend our understanding on employees' perception towards green behaviour and its practices.

\section{Acknowledgements}

The authors would like to thank to the employees who were willing to spend their time answering the survey. The encouragement received along the way from several people have kept us motivated to complete this study.

\section{Corresponding Author}

Siti Norashikin Bashirun

Faculty of Business and Management, Universiti Teknologi MARA, Melaka

E-mail: shikinbashirun@gmail.com

\section{References}

Aoyagi-Usui, M., Vinken, H., \& Kuribayashi, A. (2003). Pro-environmental attitudes and behaviors: An international comparison. Human ecology review, 23-31.

Bissing-Olson, M. J., Iyer, A., Fielding, K. S., \& Zacher, H. (2013). Relationships between daily affect and pro-environmental behavior at work: The moderating role of pro-environmental attitude. Journal of Organizational Behavior, 34(2), 156-175.

Chan, E. S., Hon, A. H., Chan, W., \& Okumus, F. (2014). What drives employees' intentions to implement green practices in hotels? The role of knowledge, awareness, concern and ecological behaviour. International Journal of Hospitality Management, 40, 20-28.

DuBois, C. L., \& Dubois, D. A. (2012). Strategic HRM as social design for environmental sustainability in organization. Human Resource Management, 51(6), 799-826.

Florea, L., Cheung, Y. H., \& Herndon, N. C. (2013). For all good reasons: Role of values in organizational sustainability. Journal of Business Ethics, 114(3), 393-408.

Hoffman, A. J., \& Georg, S. (2012). A history of research on business and the natural environment: Conversations from the field. Business and the environment: Critical perspectives in business and management, 1, 1-58.

Hicklenton, C., Hine, D. W., \& Loi, N. M. (2019). Can work climate foster pro-environmental behavior inside and outside of the workplace? PloS one, 14(10).

Kollmuss, A., \& Agyeman, J. (2002). Mind the gap: why do people act environmentally and what are the barriers to pro-environmental behavior? Environmental education research, 8(3), 239260.

Lamm, E., Tosti-Kharas, J., \& Williams, E. G. (2013). Read this article, but don't print it: Organizational citizenship behavior toward the environment. Group \& Organization Management, 38(2), 163-197.

Levine, D. S., \& Strube, M. J. (2012). Environmental attitudes, knowledge, intentions and behaviors among college students. The Journal of social psychology, 152(3), 308-326.

Lo, S. H., Peters, G. J. Y., Van Breukelen, G. J., \& Kok, G. (2014). Only reasoned action? An interorganizational study of energy-saving behaviors in office buildings. Energy efficiency, 7(5), 761-775.

Loverock, D. T., Kool, R., \& Kajzer-Mitchell, I. (2015). Workplace culture as a driver for social 
INTERNATIONAL JOURNAL OF ACADEMIC RESEARCH IN BUSINESS AND SOCIAL SCIENCES

Vol. 10, No. 6, June, 2020, E-ISSN: 2222-6990 @ 2020 HRMARS

change: influencing employee pro-environmental behaviors. In Empowering Organizations Through Corporate Social Responsibility (pp. 29-50). IGI Global.

Mei, N. S., Wai, C. W., \& Ahamad, R. (2016). Environmental awareness and behaviour index for Malaysia. Procedia-Social and Behavioral Sciences, 222(7), 668-675.

Milfont, T. L., \& Duckitt, J. (2010). The environmental attitudes inventory: A valid and reliable measure to assess the structure of environmental attitudes. Journal of Environmental Psychology, 30(1), 80-94.

Murtagh, N., Nati, M., Headley, W. R., Gatersleben, B., Gluhak, A., Imran, M. A., \& Uzzell, D. (2013). Individual energy use and feedback in an office setting: A field trial. Energy Policy, 62, 717-728.

Norton, T. A., Zacher, H., \& Ashkanasy, N. M. (2012). On the importance of pro-environmental organizational climate for employee green behavior. Industrial and Organizational Psychology: Perspectives on Science and Practice, 5, 497-500.

Norton, T. A., Zacher, H., \& Ashkanasy, N. M. (2014). Organisational sustainability policies and employee green behaviour: The mediating role of work climate perceptions. Journal of Environmental Psychology, 38, 49-54.

Norton, T. A., Zacher, H., Parker, S. L., \& Ashkanasy, N. M. (2015). Employee Green Behavior: A Theoretical Framework, Multilevel Review, and Future Research Agenda. Organization \& Environment 2015, Vol. 28(1) 103 -125. SAGE Publications.

Norton, T. A., Zacher, H., Parker, S. L., \& Ashkanasy, N. M. (2016). Bridging the gap between green behavioral intentions and employee green behavior: The role of green psychological climate. Journal of Organizational Behavior.

Ones, D. S., and Dilchert, S. (2012a), "Employee green behaviors", Managing HR for Environmental Sustainability, Jossey-Bass/Wiley, San Francisco, CA, pp. 85-116.

Ones, D. S., \& Dilchert, S. (2012). Environmental sustainability at work: A call to action. Industrial and Organizational Psychology, 5(4), 444-466.

Organ, D. W., Podsakoff, P. M., \& MacKenzie, S. B. (2006). Organizational citizenship behavior: Its nature, antecedents, and consequences. In Organizational Citizenship Behavior: Its Nature, Antecedents, and Consequences. https://doi.org/10.4135/9781452231082

Pham, N. T., Phan, Q. P. T., Tučková, Z., Vo, N., \& Nguyen, L. H. (2018). Enhancing the organizational citizenship behavior for the environment: the roles of green training and organizational culture. Management \& Marketing. Challenges for the Knowledge Society, 13(4), 1174-1189.

Phuah, K. T., Rezai, G., Zainalabidin, M., \& Shamsudin, M. N. (2012). Malaysian Perception and Attitude towards Green Concept and Going Green. Proceeding of 3rd International Conference on Business and Economic Research, Mar. 12 13, Bandung, Indonesia: pp. 401414

Sadik, F., \& Sadik, S. (2014). A study on environmental knowledge and attitudes of teacher candidates. Procedia - Social and Behavioral Sciences, 116, 2379-2385. https://doi.org/10.1016/j.sbspro.2014.01.577

Sanyal, U., Bengal, W., \& Bengal, W. (2017). Effect of organizational culture in environmental awareness on pro-environmental behaviour at workplace: $A$ new perspective on organizational sustainability. 1, 60-65. 